JQCJC VOLUME 8 ISSUE 2 (WINTER 2020)

\title{
SEEING AND RESPONDING: HOW STUDENTS PERCEIVE SCHOOL PERSONNEL TO FAIL TO RESPOND TO BULLYING
}

\author{
Ethan M. Higgins ${ }^{1}$ \\ University of North Carolina Wilmington \\ Benjamin W. Fisher \\ University of Louisville \\ Maury Nation \\ University of Vanderbilt
}

\begin{abstract}
Although research has shown that students and school personnel believe that adults respond to bullying at different rates, it is unclear why these differences occur. Using open-ended survey responses from 189 students, this study investigates why students perceive that school personnel fail to respond to bullying. Students articulated a variety of reasons for school personnel's lack of response, including ways in which they could fail to see, notice, or respond to the bullying. In turn, students used their agency to understand and counteract school personnel's lack of response. Theoretical and policy implications are discussed.
\end{abstract}

Keywords: victimization, responding, visibility, school climate, school violence

\section{INTRODUCTION}

Schools across the country have faced the issue of bullying for many years. Self-report estimates over a ten-year span indicate that $22-32 \%$ of students have experienced bullying victimization (National Center for Education Statistics, 2016). However, there is a disconnect between students and school personnel (e.g., teachers, administrators, and other school-based authority figures) in their perceptions of how bullying is recognized and addressed. Specifically, teachers believe they respond to most bullying scenarios whereas students claim that teachers respond infrequently (Dake, Price \& Telljohann, 2003; Mishna, Scarcello, Pepler \& Wiener, 2005; Pepler, Craig, Ziegler \& Charach, 2009; Stockdale, Hangaduambo, Duys Larson \& Sarvela, 2002; Varjas, Meyers, Bellmoff, Lopp, Birckbichler \& Marshall, 2008; Vaillancourt, McDougal, Hymel, Kryhsman, Miller, Stiver \& Davis, 2008). For instance, Pepler and

${ }^{1}$ Ethan M. Higgins, Ph.D., Department of Sociology and Criminology, University of North Carolina Wilmington, 601 S. College Rd., Wilmington, NC 28403, higginse@uncw.edu. The study has IRB approval from Vanderbilt University. 


\section{HIGGINS ET AL.}

colleagues (2009) found that teachers claimed to intervene in $85 \%$ of bullying incidents, whereas only $35 \%$ of students claimed teachers intervene.

The reason for the discrepancy between students' and school personnel perceptions about the extent of intervention is not entirely clear. One common explanation for this discrepancy is simply that school personnel are present less and thus see bullying less than students do (Atlas \& Pepler, 1998; Craig \& Pepler, 1997; Hanish \& Guerra, 2000; Mishna et al., 2005; Newman, Murray \& Lussier, 2001). In a literal sense, school personnel may be present less than students in bullying situations. However, prior research has largely neglected to address "seeing" as a more interpretive process in which school personnel have considerable influence upon constructing whether and how bullying requires intervention (Hazler, Miller, Carney \& Green, 2001) or interpersonal factors influence students to refrain from seeking help from school personnel in the school context (Newman et al., 2001). This alternate framing of seeing bullying may help elucidate the considerable gap between students' and teachers' reports about the frequency of school personnel intervening in bullying.

The following study uses grounded theory methodology to investigate students' perceptions of how school personnel see and respond to bullying. Theoretically, this paper contributes to the literature on response in bullying scenarios by identifying "seeing" as a coconstructed precondition of response to bullying (Swearer \& Doll, 2001). A primary consequence of being bullied is a loss of agency as one is unable to defend one's self in the school environment (Farrington, 1993; Sercombe \& Donnelly, 2013). In turn, a loss of victim agency is compounded when school personnel fail to respond. Understanding seeing and response within a social-ecological perspective elucidates how students may feel invisible and then work to reclaim visibility. Within these frameworks and emerging from the data, this paper argues that school personnel seeing student victimization is a precondition to response and defending one's self. In this way, as bullying is a co-constructed process in schools (Pianta \& Walsh, 1996), responding to bullying is also a process co-constructed by students, school personnel, and other actors in the school.

\section{Reasons School Personnel Fail to See and Respond}

Studies have frequently documented the differences between student and school personnel perceptions of responding to bullying (Dake et al., 2003; Mishna et al., 2005; Pepler et al., 2009; Stockdale et al., 2002; Varjas et al., 2008; Vaillancourt et al., 2008). However, research is relatively scant in exploring how and why this discrepancy exists. Although school personnel do not intervene with consistency for a range of reasons (Atlas \& Pepler, 1998), they

often fail to intervene because they are simply not present during bullying interactions (Hanish \& Guerra, 2000) or because they are unaware bullying is occurring (Newman et al., 2001; Mishna et al., 2005; Hazler et al., 2001). Thus, prior literature suggests school personnel often do not respond because they fail to see bullying (Dake et al., 2003; Hanish \& Guerra, 2000; Newman et al., 2001; Mishna et al., 2005). Failing to see may manifest both in literal failures to be present during the moments of a bullying interaction or interpretively through perceptual discrepancies between students and school personnel.

An interpretive explanation of a failure to see is that students and school personnel have internalized different working definitions of bullying and response that cause actors to recognize them differently. Research offers mixed evidence regarding the extent to which students' and school personnel' definitions of bullying converge. On one hand, in line with adult-centered 
definitions of bullying — including dimensions of repetition, intentionality, and power imbalance (Olweus, 1993) - some studies have found that students define bullying as physically aggressive behaviors (Arora \& Thompson, 1987; Boulton, Trueman \& Flemington, 2002; Smith \& Levan, 1995). However, other studies found differences across the two groups (Elinoff, Chafouleas \& Sassu, 2004; Varjas et al., 2008). For example, in contrast to adult-based definitions, students have been found to focus on the consequences or negative effects of the interaction rather than the characteristics of the interaction itself (Monks \& Smith, 2006; Varjas et al., 2008). In turn, some researchers have called for a need to expand the definition of bullying beyond adultcentered interpretations to include the perceptions of students (Elinoff et al., 2004; Farrington, 1993; Varjas et al., 2008).

To provide a more complex understanding of bullying and response, researchers have couched definitions in the school context within multiple contemporary theories that highlight student perspectives. For instance, a social-ecological approach to understanding bullying and response suggests that a dynamic range of actors within the school constructs both bullying and responses to bullying (Bronfenbrenner, 1977; Hong \& Espelage, 2012). Within the school environment, constituent stakeholders are forming and reforming a working definition of bullying as well as determining the appropriate response to bullying. Problems of bullying and victimization are negotiated among the range of actors where each actor engages in a process of "reciprocal interplay" (Swearer \& Doll, 2001, p.10) which allows individuals to contribute to a working definition of bullying and negotiate appropriate responses. Thus, the construction of bullying and responses to bullying come to fruition through a range of interpersonal interactions among individuals within the school, and in turn, individual decisions are both informed by and help to influence the school context more broadly.

Applying a critical lens to a social-ecological model suggests that some actors in the school environment hold more power than others to define bullying and response (Frisén, Holmqvist \& Oscarsson, 2008; Hazler et al., 2001; Mishna et al., 2005; Vaillancourt et al., 2008). For example, school personnel can act as definitional gatekeepers, where through sanction or acknowledgment, they may legitimize a victim's experience of bullying. Thus, defining bullying is often a complicated task of unraveling distinctions between what adults and students have counted as bullying. In a similar vein, research on bystander intervention has identified how outside actors can play powerful roles in sustaining or preventing bullying (Twemlow, Fonagy \& Sacco, 2004). As such, bystanders may act as reinforcers of bullying or defenders of victims (Polanin, Espelage \& Pigott, 2012), and thereby produce visibility for victims or silence them. From these theoretical perspectives, a failure to see bullying may be read as a denial of reciprocal interplay (Swearer \& Doll, 2001) in which a student's experience of bullying is delegitimized through the non-response of bystanders (e.g., school personnel) that hold power in the school environment.

Indeed, prior literature has demonstrated that from an adult-centered perspective, school personnel make decisions when deciding to intervene in a bullying incident (Atlas \& Pepler, 1998; Dake et al., 2003; Mishna, Antle \& Regehr, 2004; Pepler et al., 2009; Stockdale et al., 2002; Ziegler \& Rosenstein-Manner, 1991). For instance, teachers are less likely to intervene if they blame the victim for the altercation (Mishna et al., 2004) or if they are complicit in the bullying scenario (McEvoy, 2005; Whitted \& Dupper, 2008). Additionally, teachers' understandings and definitions of bullying affect whether they are likely to respond (Boulton, 1997; Mishna et al., 2005; Siann, Callaghan, Lockhart \& Rawson, 1993). That is, teachers are 


\section{HIGGINS ET AL.}

more likely to intervene or react when incidents are congruent with their internalized, typically adult-oriented definitions of bullying.

Although school personnel retain the ability to make decisions about responding, student agency may still play a role in eliciting a response from school personnel and producing visibility in the social context of the school environment. A central negative consequence of being bullied involves an oppressive quality (Farrington, 1993) wherein students cannot defend themselves from the bully. In this sense, the victim is bullied into a loss of agency and in which they cannot occupy a healthy place in the social structure (Sercombe \& Donnelly, 2013). Within the social-ecological framework, a loss of agency involves removal from the social context as individuals lose their ability to contribute to the working definition of bullying and response. In contrast, from the merged social-ecological and critical perspectives, reclaiming one's agency involves producing visibility that compels a response. Although bullying literature has traditionally focused on a central element of bullying in which victims are unable to defend themselves due to constructed power imbalances, students may also retain the ability to reset power differentials to reclaim their agency - and in a theoretical sense, their reciprocal interplay - by producing visibility.

\section{Current Study}

Although prior research has identified potential reasons why students and school personnel might disagree about the extent to which school personnel respond to bullying, these studies have largely neglected students' agency and the extent to which they are able to exert power. If students attempt to make their bullying victimization known to school personnel but do not receive an adequate response, they may feel that their problems have been delegitimized and that their agency has been diminished. In this manner, from a student-centered perspective, a response from school personnel provides a sense of legitimacy. As such, this study focuses on students' perceptions of why school personnel failed to respond to bullying with an emphasis on students' agency. It examines the ways in which school personnel are depicted to delegitimize through failing to see or respond-students' victimization experiences. To our knowledge, this study is among the first to investigate students' perceptions of the reasons for the welldocumented gap between students' and school personnel's perceptions of the frequency with which school personnel respond to bullying. This study investigates two research questions: (1) In what ways do students perceive school personnel to delegitimize their bullying experiences through not responding? (2) How do students understand non-response and counteract a lack of response through creating visibility?

\section{METHOD}

\section{Sample and Data Collection}

The data used in this study come from a subset of responses to a statewide school climate survey of 64,992 middle and high school students from 127 public high schools within 27 school districts across a Southern state in the United States. Participation in the study was not mandatory for all schools in the state; the sample of schools included here represents school districts that chose to undergo data collection and technical assistance around various initiatives aimed at improving school climate. Students completed the surveys online while they were at 
school. Students' responses were de-identified and stripped of all demographic information before the researchers had access to the data. Following a series of fixed-choice questions about school climate, students were given an option to provide an open-ended response to the prompt "If you have ever been bullied or harassed at school, please tell us a little bit about the incident and why you think you were targeted." After removing all students who did not respond or whose responses contained only the word "No," 8,531 responses remained. These responses were further refined using the process described below to yield a final analytic sample of responses from 189 students. Note that students were not specifically asked about school personnel responses to bullying; this was a theme that emerged from the data without prompting students to address this phenomenon.

\section{Data Analysis}

Four coders generated a coding scheme for analyzing the data. First, the coders independently read 300 student responses and created a set of codes that reflected the most prevalent themes using open coding. Using this initial set of codes, the coders next read and coded 100 responses, reconvening again to compare their coding. The coding scheme was revised based on discrepancies in the coding, as well as new themes that emerged after reading additional student responses. This process was repeated until the coders reached an acceptable interrater reliability (average $\kappa$ across all codes $=.88$ ). After establishing this final coding scheme, the four coders processed all 8,531 student responses using the coding scheme that was developed. To maintain consistency in coding over time, the coders used the constant comparative method (Glaser, 1965), where the coding decision for a given response was compared to both the definition of the code and prior responses that had been assigned the same code. All responses were double-coded and any discrepancies were discussed by the two coders and resolved by consensus. All coding was conducted using DiscoverText, a web-based program for analyzing text data.

One of the codes identified student responses that included language about any schoolbased employee - either faculty or staff - whose actions or inactions facilitated the experience of bullying victimization for the student respondent. Note that this code did not include overt acts of bullying by the adults. This code was applied to the 189 student responses that constitute the analytic sample for this study. Across the sample, the open-ended responses ranged from brief short answer responses to multiple paragraphs in length. All responses were left unaltered in order to better represent the voices of each respondent. These 189 responses were entered into a single document for analysis, which yielded the typology that informed the current study.

Following the grounded theory methodological approach (Charmaz, 2008), we used two steps of inductive analysis: open coding and axial coding. First, open coding involves conducting a line-by-line reading to explore the data, read each student's response and provide individualized analysis. The purpose of this first stage was to find emerging themes in the failure of school personnel to intervene. Second, we conducted axial coding. This step involved searching the qualitative responses for systematic patterns and themes and making parallel connections between sets of individualized codes. In the presentation of our findings below, several quotations from students' responses are presented. These responses were selected for their representativeness of each theme and are provided exactly as the students typed them. 


\section{FINDINGS}

The following findings demonstrate how students explained school personnel's lack of response to bullying. Students perceived that school personnel engaged in an array of behaviors that prevented them from responding, ranging from passively failing to recognize bullying to actively attempting not to recognize bullying through various actions or narrative techniques. These descriptions offer a counter-narrative to the conventional explanation in the literature that school personnel are not present and, therefore, cannot see by demonstrating experiences in which students perceived that school personnel were present and saw the bullying but still failed to respond. The findings are presented in two parts. The first part provides a typology of the ways students portrayed school personnel as failing to respond to bullying. The second part examines how students explained and counteracted the school personnel's failure to respond.

\section{A Typology of Not Responding}

Social Status. A common student construction of not responding took place in merging the inability of school personnel to recognize bullying with the social status of the person who engaged in bullying behaviors:

The so-called popular kids seem to have it much easier at this school than any of the others I have been called 'fat' by football players, multiple times, and teachers I KNOW, have hear it, and don't do anything about it. I don't find it quite fair that they don't take bullying as dramatic as they should (Student 39).

Students recognized that the social status and personal characteristics of the individual doing the bullying disguised the nature of their actions towards others in the eyes of school personnel:

.... a boy who was a year ahead of me and also a popular redneck, would go around and pick on the unpopular kids in a very unfair way, sometimes making fun and laughing when they cried, but yet our principles were so oblivious to his true nature that they did nothing and were even friends to him (Student 10).

In these previous passages, students merged the notion of the school personnel's lack of response to the event with students' social status within the school.

The protected social status of some students - and by contrast, the vulnerable social status of other students - played into the social ecology of the school in which school personnel's failure to respond to bullying reified extant social stratification and allowed victimization to occur without formal sanctions. Students noted that the passivity of school personnel in recognizing bullying and apprehension in confronting particular individuals due to their social status contributed to the lack of response to students' claims about bullying. In the dynamics of bullying, students were aware of how one's status affected response:

I am cadet in the JROTC program here at the high school and there have been many times where I have felt bullied by the others cadets because they could get away with it and because they did not like me. A lot of times bullying gets overlooked because of who is doing the bullying (Student 7). 
These social statuses were often explained by achievements or attributions based on family or community factors. Achieved statuses most often came from athletics:

...he was captain of the sports team and therefore he couldn't get in trouble. I went to the teachers and they ignored my complaint because it was that student although I had evidence and people to back my statement up. He continues to bully others with no fear of being caught because the school is extremely bias towards its sports players (Student 2).

However, status could also be attributed based upon familial circumstances:

[After a fight due to bullying] Not once was I asked if I was okay, or if I was hurt. I received 5 days OSS (out of school suspension) whereas the thief received none. This is because it was Dr. Susan's (pseudonym) son, former superintendent of the school system in which I now reside (Student 22).

In these circumstances, the protected status of the bully was seen as mitigating the sanction or public recognition of the bullying event. Through understanding the school's context - in particular, the social stratification within the school - many students described social status as a reason that school personnel failed to intervene in their bullying experience.

What Counts as Bullying? Corresponding with literature deeming adult definitions of bullying as overly restrictive (Arora, 1996; Farrington, 1993; Olweus, 1993), students indicated that school personnel failed to recognize bullying outside of limited definitional parameters, which undermined their capacity to recognize nonphysical forms of bullying. Across the sample, students who implicitly maintained inclusive definitions of bullying that focused on its negative effects remarked that school personnel often did not validate emotional, social, or relational aggression as bullying. This gap between students' and school personnel's understanding resulted in complaints that non-physical bullying was not counted as true bullying or went unheard by school personnel: "Adults at this school act like they care about bullying, but they don't really do anything to control or stop the bullying if it is an emotional attack" (Student 32).

As noted in the literature, school personnel are more likely to characterize bullying through conventional definitional components such as repetition, direct rather than indirect bullying, and intentionality and power imbalances (Olweus, 1993). Yet, as Guerin and Hennessy (2002) have maintained, bullying can be understood as based on the harm of the experience, rather than if the event meets strict definitional criteria. Although school personnel may fail to recognize different modalities of harassment as bullying, the experience still is recognized by students as bullying: 'I'm a cross dresser and I'm Pagan-Wiccan. I'm heavy set and I like what I like. I'm harassed because of my weight and personality. But nobody ever does anything unless someone is physically hurt" (Student 30). Students noted that bullying behaviors often ran tangentially to conventional understandings of bullying by school personnel and thus remained invisible to them. Other harmful modalities of bullying (e.g. sexual/emotional) were minimized through conventional, adult-based definitions of bullying:

Minding my own business one day, a guy grabbed me in sexual way and then made sexual comments. The same guy has made several sexual comments throughout my 


\section{HIGGINS ET AL.}

high school career. Even though I have reported him several times for the comments but no action was taking until the physical harassment (Student 31).

In the previous passage, the student noted the discrepancy in seriousness towards different forms of harassment (i.e., verbal versus physical). Despite the harm caused to the individual, school personnel refrained from responding or even actively dismissed the claims because they failed to read non-physical actions as sufficiently harmful. In each of the excerpts in this section, students connected definitional differences with school personnel's responses to their victimization. That is to say, the experiences of the victim were narratively linked with their failure to be recognized as legitimate bullying in the co-constructed definition within the school environment.

Zero Tolerance. Another technique of not responding that emerged from the data came in the blanket zero-tolerance policies that were perceived by students as unhelpful to bullying victims. Zero-tolerance policies are generally defined as "a method of sending a message that certain behaviors will not be tolerated, by punishing all offenses severely, no matter how minor" (Skiba \& Peterson, 1999; Skiba \& Knesting, 2001), and often set forth predetermined taxonomies of offense and punishment mandating particular responses to offenses. Although zero-tolerance policies began as a way of limiting the presence of weapons and drugs in schools, some schools eventually expanded these policies to include other offenses such as fighting and bullying (Skiba \& Knesting, 2001; Skiba \& Peterson, 1999). Interestingly, among the students in this sample, zero-tolerance policies were understood as supplanting the requirement for a school personnel's response. Students narratively linked the existence of zero tolerance with the school personnel tendency to "look past" the victimization: "This school does nothing to help or stop bullying. They say they have a zero-tolerance for it, but that is a lie. They look right past it and do nothing" (Student 58).

Student accounts revealed constructed scenes in which the zero-tolerance policy itself was the response to bullying and thus precluded school personnel from having to act. Zero tolerance became the action that stood in place of having to intervene:

The next day she texted my boyfriend and told him that she was going to 'Fuck my face up!' I went to the principal and he told me to ignore her, then she went to the principal and showed him messages I sent her, but she deleted the ones she sent me at the beginning of the school year. He said that there is a no bullying policy and she got no punishment for threatening me or lying about the messages (Student 60).

Students expressed that having a zero-tolerance policy meant that school personnel no longer were required to act or provide sanction since they had already claimed their stance on the issue:

I felt ashamed to even walk in to the ROTC classroom when he was in there. The sad thing is, is that all he got is warning and in ROTC I almost got in trouble for saying something about it. I was very angry that in a school with a zero tolerance for bullying he got away with bullying me (Student 20).

Ironically, zero-tolerance policies were seen as undermining individual protections against victims. Zero-tolerance policies may exacerbate the harm elicited through imposing rigid conventional adult-based definitions of bullying. For instance, a zero-tolerance policy that 
maintains strict and rigid punishments for bullies might decrease the likelihood that minor bullying incidents or unconventional bullying forms (e.g., emotional, social, relational) are recognized and punished. Thus, if bullying must be met with harsh punishments without consideration given to contextual or mitigating factors, students viewed school personnel as being less inclined to respond to different degrees of bullying.

The "If It Happens Again" Mentality. At times, school personnel were confronted with bullying interactions that victims brought directly to their attention. In these circumstances, school personnel were forced to recognize the existence of the bullying. Students recounted a technique in which school personnel would claim to respond but not take action or provide sanction. These typically manifested in the form of a warning, where school personnel would mandate that if it happened again, then they would act. This finding is in line with the literature that notes the crux of adult-based definitions often rests on repetition (Olweus, 1993) as a cornerstone of bullying. As one student said:

This guy would always touch me in an inappropriate way and the teacher said if it happened again to tell him (the teacher) and he would do something about it. But truth be told it should have been dealt with to begin with. And it's happening to more girls than me by the same guy, and the teacher said the same thing (Student 11).

Students claimed that school personnel insisted that a behavior must happen at a higher frequency in order to be considered bullying or to warrant a response. These instances were often marked with warnings that came prior to sanction or public acknowledge of harassment:

Last year in $8^{\text {th }}$ grade I was doing my work then boys in my classes like to pick on me talk about me and call me bad names. So I would tell the principal then they would say that they will get this person. Then the same person would do the same thing (Student 13).

Students noted this tendency for school personnel to mark bullying with pre-sanction or pre-acknowledgment (i.e., if they do it again, then it will be taken seriously). In the following quote, the student's scenario of harassment indicates that teachers would continually give warnings with no limit in which formal sanctions occurred: "These little retarded boys get on my nerves because they are so childish and are always playing in class. It really does distract me and usually makes me have a bad day. Teachers usually give them warnings and that it" (Student 12). Despite the disruption, school personnel often responded to student complaints with postponement. Interestingly, student accounts demonstrated that school personnel's postponement of sanction was linked with conceptions of time:

I was harassed at school by a boy, during band last year. He touched me and told me my boobs looked big. This went on every day in band. Was one perverted joke after another. I told the band director, she said she would do something about it, but she never did! I felt horrible every day! (Student 15).

As this student demonstrated, the danger of the "if it happens again" mentality is that it can be disrupted by breaks in time or space in the school. For instance, sentiments like it "usually makes 


\section{HIGGINS ET AL.}

me have a bad day" and "I felt horrible every day" indicate that response warnings had delineations that caused them to expire and be reset in new environments or time frames (e.g., the student moves spaces, the following day the same class meets again). In addition, a warning that repetitive bullying behavior will result in sanction may reset once a class period ends, the school day concludes, or if the student switches to a new classroom guided by a different teacher. If warnings reset each day, then a student can be bullied for the entirety of their school career: "It has not stopped and will only stop once we all walk across the stage and graduate" (Student 58).

Unjust Punishment. Another technique of failing to respond came in the form of applying punishment to both parties - the bully and the victim. Students that experienced bullying and went unseen were forced to respond in some manner, which resulted in double punishment. Students depicted that school policies asserted that victims themselves were at least partially responsible for the result in the bullying interaction: "I feel the principals didn't listen to me. Their picking (bullying) lasted my entire freshman year until they graduated. My mom had came up to my school numerous times and nothing was ever done about the situation. Everything always came back on me" (Student 16). Students depicted scenarios in which school personnel applied punishment to victims' minor rule violations or attempted defense against victimization. In this sense, school personnel marked the victim as well as the bully as a rule violator. In turn, the victim's claim of being victimized is effectively delegitimized because their response violated school rules. Students may feel in such situations that an unjust punishment consists of a second victimization that has been levied against them by school personnel:

School officials do little help because it really seems like they don't care. They just do what is convenient for them and treat us like an interruption, and do not give fair punishments to bullies. If people fight back, the instigator isn't punished more than the victim and that's not right (Student 17).

From a student perspective, school personnel were constructed as failing to respond until physical retaliation occurred from the victim. When a victim fought back against bullying and both parties were involved in the altercation (often because of nonresponse from school personnel), then both individuals were constructed as equally breaking the rules, which effectively delegitimized the original complaint of bullying. Thus, across the sample students noted the tendency for school policies and rules to indicate a re-victimization, where victims could be sanctioned for being victimized or claims of bullying could be delegitimized.

\section{Seeing and the Need to Respond}

The previous section demonstrated a typology of how students perceived school personnel to fail to respond to bullying. The following section addresses two items: 1) how students explained non-response; and 2) how students counteracted this lack of response. Specifically, the following section focuses on the relationship between seeing and lack of response from school personnel and on how students explained their ability to reclaim reciprocal interplay through producing visibility in the social context.

Seeing, Noticing, and Responding. In the previous section, students lamented the failure of school personnel to respond to bullying despite seeing the incident. Thus, for students, the concepts of seeing and responding were often two sides of the same coin, where the crux of delegitimization rested not on "if" school personnel could see bullying but "how." This visibility 
dynamic featured a couple of distinct elements. On the one hand - corroborating the first section of the results - students indicated that school personnel could see victimization in a literal sense but fail to respond: "My ex-boyfriend would yell at me, and sometimes wouldn't leave it alone in the hall ways. Not one time did a teacher tell him to stop and they did see it happen" (Student 54). At other times, the relationship between school personnel viewing victimization and a failure to respond was attributed to factors that obfuscated the pathway between seeing and response: "...because of me just being the nice person that I am and I feel like that they teachers see it but don't say anything about it" (Student 56). Such student accounts complicate conventional understandings of response by indicating that seeing does not always lead directly to response and that the connection between seeing and response may be disrupted by intermediary factors.

These intermediary factors were explained by the phenomenon of "noticing"- a term frequently used by students - to illuminate the underlying tension between visibility and response. Noticing, a parallel concept to seeing, referred to a process in which school personnel saw the bullying (either literally, interpretively or both) and recognized it as meriting some type of response. Students suggested that the act of seeing bullying was not enough to automate a response from school personnel; noticing was an intermediate step beyond seeing in which school personnel could be compelled to respond: "I don't even do anything to deserve it, but when boys harass me they usually say something sexual or try to grab me. It's pathetic how the teachers don't even notice or they just look and look away and don't do anything" (Student 35). Indeed, the addition of "noticing" suggested a broader visibility dynamic at play, where different forms of seeing manifested in the school environment. This intermediate step provides the point of departure for the following section investigating how students counteracted being seen but not responded to and the attendant sense of delegitimization. In other words, in situations in which school personnel saw or noticed bullying but did not respond - that is, "look and look away"students could use visibility to compel school personnel to notice by making victimization undeniable in the social context of the school.

Fighting to be Noticed. As demonstrated, students depicted an array of techniques used by school personnel not to respond to bullying despite seeing it. Yet, these quotes also reveal how noticing is central to understanding response in a social-ecological framework. Quotes about seeing and noticing may be read as an interaction where actors negotiate the visibility of victimization and whether school personnel are compelled to respond. In this vein, noticing was a central mechanism that students could exploit in an effort to remedy situations in which their victimization was seen but still lacked effective response. By negotiating their visibility, students could counteract non-response and compel school personnel to notice and respond by creating a disruption visible to a range of actors. For bullied students, these disruptions could manifest in physical or emotional outbursts as reactions to their invisible victimization.

Specifically, students could become visible by drawing attention through violating school rules to reclaim reciprocal interplay. That is, when school personnel would "look and look away," victimization could still be made visible through other means. In turn, from a socialecological perspective, fighting to be seen represents a student exercising agency to reclaim reciprocal interplay, where disruption forces visibility. Understanding the parallel concepts of seeing and responding as the basis of a social-ecological interaction emphasizes the harm of not being seen or having to fight to be noticed by school personnel: 


\section{HIGGINS ET AL.}

I believe that the faculty should be more proactive towards bullying instead of just blowing off the incent because some people do not taking bullying well and they do not tell a adult what is happening to them and they take matters into there own hands and someone ends up getting ingerd (Student 14).

In the previous example, a loss of agency — and theoretically, of reciprocal interplay-was narratively counteracted by students' efforts to "take matters into there own hands." Hypothetically, the student leverages physical and visible bodily injury against the lack of proactive concern around bullying from school personnel. The student alludes that victims may make bullying and victimization - that school personnel have no urgency to uncover or revealvisible through injury. Although non-physical forms of bullying can be made invisible by school personnel "looking and looking away," physical injury produces a visible mark on the body and disruption in school environment that cannot be ignored.

Indeed, beyond these hypothetical narrations, students also indicated real efforts of physical retaliation as the culmination of regular victimization interaction with bullies. Despite their victimization not being immediately seen by school personnel, students' physical retaliation and emotional outbursts provided leverage to force school personnel to notice. In this sense, victims could disrupt the social context forcing the range of actors to notice and implore school personnel to respond in one way or another: "One day, when the problems finally became overwhelming for me, and I had already politely asked the students to stop, I completely lost it. I began yelling at the students who were picking on me, and it became a distraction to the rest of the class" (Student 40). In a social-ecological framework, acting out represents the use of agency in which students create visibility by breaking the rules.

It is also the case that students could recast non-physical forms of bullying as physical to elicit a response. As shown, students charged school personnel and contextual factors (e.g., zerotolerance policies) with constructing definitional parameters on bullying wherein physical interactions were defined as bullying and other forms were not. From a student perspective, if adult-based definitions only conceptualize physical victimization as requiring a response, then victims must recreate unseen victimization through a physical mode to create visibility and elicit a response: "got in a fight with him a was suspended and am now being sued for assault because the principal would do nothing about it when this begun" (Student 26). Reading this excerpt within a logic of reciprocal interplay, the student recounts a failure for the principal to recognize the student's voice and agency; once the student's reciprocal interplay was denied they physically disrupted the social context and forced a response from school personnel. Although it may be the case that self-defense was central to the student's intentions (it is unclear in the text), the immediate production of visibility from physical retaliation can be read as escalating a bullying interaction to the point that the student regained agency after being made invisible by the principal's failure to respond.

Moreover, students identified that circumventing a lack of being seen by fighting to be noticed could result in worse disciplinary outcomes for the victim. For some students, gaining agency in the school's reciprocal interplay became a contest of shifting the way school personnel saw the interaction so that they would recognize it as bullying. Thus, reacting to emotional or social victimization by fighting back shifted visibility, yet also increased potential disciplinary outcomes: "It is still going on. A fight has happened and I was the one that got in trouble not the person that was bullying me" (Student 24). The previous quotes indicate that reclaiming reciprocal interplay often comes at a great cost (e.g., one was sued for assault). Thus, this study's 


\section{JQCJC VOLUME 8 ISSUE 2 (WINTER 2020)}

findings suggest that once reciprocal interplay has been denied, some students are willing to create visibility even at great personal cost.

\section{DISCUSSION}

This study provides increased attention to the workings of seeing and responding. Particularly, data from this study complicate conventional understandings of visibility in bullying by introducing an emerging student-centered concept of "noticing." As explained by students, their ability to speak to the community and to levy defense against victimization relies on school personnel's ability to move from seeing to noticing to responding, leading some students to redraw their experience in ways more likely to be visible. In this way, seeing and noticing within a social-ecological framework of bullying identifies how student agency is facilitated through school personnel that has the authority to sanction-producing the need for co-constructing visibility. Making one's victimization visible for school personnel, then, is the act of reclaiming reciprocal interplay (Swearer \& Doll, 2001) — or being recognized in the social context—through a gatekeeper to the larger environment.

In turn, students perceived that school personnel have the potential to opt out of response in multiple ways. Thus, a visual depiction of this system can help understand this phenomenon (provided in Figure 1). The decision-making points for school personnel are represented in Figure 1, whereby the concept of noticing indicates that response consisted of multiple possible pathways: school personnel could either (a) not see, (b) see but not notice, (c) see, notice, and respond, or (d) see, notice, and not respond. Two of these options proved most egregious for respondents. In the case of see, not notice and not respond, school personnel are depicted as not responding because the student has not gained enough legitimacy as a victim to compel school personnel to intervene. Additionally, in the case of see, notice and not respond, it may have been the case that school personnel were willing or even intended to respond, but did not because of the larger climate. This component of visibility is depicted in Figure 1 and indicates that school environmental factors (e.g., school political/cultural climate) bear on school personnel responses to bullying.

\section{Policy Implications}

This study's findings concerning students' perceptions of school personnel failure to see, notice, and respond to bullying may be useful for providing information about appropriate ways to respond to marginal instances of bullying. Conventionally, policy implications for improving authority figure response are often based on this line of reasoning that increased presence equals increased response. Policies focusing on a failure to see bullying often involve techniques to "increase teacher and staff awareness of the extent of the problem" (Hanish \& Guerra, 2000, para. 23) as well as "create a warm and positive environment for children coupled with close monitoring of children's interactions" (para. 24). These findings challenge conventional implications by suggesting that seeing bullying is not always enough to warrant a response. Put another way, school personnel can look at bullying and still be blind to it.

Whereas some interventions address response by increasing the physical presence of school personnel, our findings suggest that addressing intermediate factors that obstruct the process of seeing and responding is necessary. For instance, in the "if it happens again" theme, school personnel were blinded when classes ended and students left. A conceptual implication 


\section{HIGGINS ET AL.}

involves improving communications across divisions in school spaces-such as from one classroom to another. Likewise, blindness is likely also constructed by a broader context. For instance, zero-tolerance policies that mandated specific responses rather than individualized action constructed blindness. Arguably, zero-tolerance policies have broad implications for manipulating seeing, noticing, and responding. These policies produce a standardized definition of bullying that strips the ability to participate in reciprocal interplay from both students and school personnel. Our findings suggest that refraining from imposing structural definitions of bullying and response allows school personnel to reduce bullying victimization that often falls through the cracks.

\section{Limitations}

The findings in this study are in danger of overestimating the number of students who corroborate these experiences and of those students who are willing to "take matters into there (sic) own hands." The data in this study come from a relatively small group of students who reported delegitimization from school personnel. Additionally, student responses are part of a larger survey where the research question was not prompted. For this reason, student experiences are not representative of the student experience, and it is possible that students who replied to the open-ended survey question experienced more serious incidents or felt more strongly about their victimization than others. Nonetheless, these overlooked experiences provided an opportunity to investigate unconventional experiences by which school personnel see but do not respond and moments in which students resist.

Additionally, the visibility dynamic is something that emerged from these bullying experiences which are often overlooked, imploring a need to study mechanisms that prevent responses to bullying that often fall into the unseen margins of large datasets. Thus, the "visibility" vernacular that emerged from the data is helpful to situate student responses within a theoretical framework, wherein students are simultaneously part of a social-ecological environment and at times, lack the power to influence it. Nonetheless, as our findings indicate, students found ways to exert agency to construct visibility even when school personnel nonresponse rendered them unseen in a theoretical and practical lens.

\section{CONCLUSION}

This study contributes to the literature on responses to bullying by exploring reasons for the well-documented discrepancy between school personnel's claims that they intervene frequently and students' claims that school personnel fail to do so (Dake et al., 2003; Varjas et al., 2008; Vaillancourt et al., 2008; Ziegler \& Pepler, 1993). Corroborating previous literature, the first section of the findings found that students perceived school personnel frequently failed to respond. Across this study's sample, student perspectives indicated that school personnel used a range of mechanisms to avoid intervention. In the second section of the findings, these themes suggested that students were able to recognize and navigate power differentials in the school by acknowledging and using the dynamics of visibility (i.e., seeing, noticing and responding). This study has also couched visibility and the need for a response within a merged social-ecological and critical perspective. By couching "seeing" within a social-ecological and critical perspective, we may observe how student agency is (de)constructed in the school context and how students may exert power in different manners to reclaim it when it has been lost. Perhaps unlike other 


\section{JQCJC VOLUME 8 ISSUE 2 (WINTER 2020)}

actors in the school-yet like other marginalized groups-individual student agency is intimately interwoven with constructing visibility for their victimization.

\section{REFERENCES}

Arora, C. M. (1996). Defining bullying towards a clearer general understanding and more effective intervention strategies. School Psychology International, 17, 317-329.

Arora, C. M. J., \& Thompson, D. A. (1987). Defining bullying for a secondary school. Educational and Child Psychology, 4, 110-20.

Atlas, R. S., \& Pepler, D. J. (1998). Observations of bullying in the classroom. The Journal of Educational Research, 92, 86-99.

Boulton, M. J., Trueman, M., \& Flemington, I. (2002). Associations between secondary school pupils' definitions of bullying, attitudes towards bullying, and tendencies to engage in bullying: Age and sex differences. Educational studies, 28, 353-370.

Boulton, M. J. (1997). Teachers' views on bullying: Definitions, attitudes and ability to cope. British Journal of Educational Psychology, 67, 223-233.

Bronfenbrenner, U. (1977). Toward an experimental ecology of human development. American Psychologist, 32, 513-531.

Charmaz, K. (2008). Grounded Theory as an Emergent Method. In S.N. Hesse-Biber \& P. Leavy (Eds), Handbook of Emergent Methods (pp. 155-172). New York: The Guilford Press.

Craig, W. M., \& Pepler, D. J. (1997). Observations of bullying and victimization in the schoolyard. Canadian Journal of School Psychology, 13, 41-59.

Dake, J. A., Price, J. H., \& Telljohann, S. K. (2003). The nature and extent of bullying at school. Journal of School Health, 73, 173-180.

Elinoff, M. J., Chafouleas, S. M., \& Sassu, K. A. (2004). Bullying: Considerations for defining and intervening in school settings. Psychology in the Schools, 41, 887-897.

Farrington, D. P. (1993). Understanding and preventing bullying. Crime and justice, 17, 381458.

Frisén, A, Holmqvist, K., \& Oscarsson, D. (2008). 13-year-olds' perception of bullying: Definitions, reasons for victimisation and experience of adults' response. Educational Studies, 34, 105-117.

Glaser, B. G. (1965). The constant comparative method of qualitative analysis. Social problems, 12, 436-445. 


\section{HIGGINS ET AL.}

Guerin, S., \& Hennessy, E. (2002). Pupils' definitions of bullying. European Journal of Psychology of Education, 17, 249-261.

Hanish, L. D., \& Guerra, N. G. (2000). Children who get victimized at school: What is known? What can be done? Professional School Counseling, 4, 113-119.

Hazler, R. J., Miller, D. L., Carney, J. V., \& Green, S. (2001). Adult recognition of school bullying situations. Educational Research, 43, 133-146.

Hong, J. S., \& Espelage, D. L. (2012). A review of research on bullying and peer victimization in school: An ecological system analysis. Aggression and Violent Behavior, 17, 311-322.

McEvoy, A. (2005, September). Teachers who bully students: Patterns and policy implications. In Teachers who bully students. Presentation to the Conference on Persistently Safe Schools-Philadelphia (September 11-14. 2005).

Mishna, F., Antle, B. J., \& Regehr, C. (2004). Tapping the Perspectives of Children Emerging Ethical Issues in Qualitative Research. Qualitative Social Work, 3, 449-468.

Mishna, F., Scarcello, I., Pepler, D., \& Wiener, J. (2005). Teachers' understanding of bullying. Canadian Journal of Education, 28, 718-738.

Monks, C. P., \& Smith, P. K. (2006). Definitions of bullying: Age differences in understanding of the term, and the role of experience. British Journal of Developmental Psychology, 24, 801-821.

Newman, R. S., Murray, B., \& Lussier, C. (2001). Confrontation with aggressive peers at school: Students' reluctance to seek help from the teacher. Journal of Educational Psychology, 93, 398.

Olweus, D. (1993). Bullying at school: What we know and what can we do. Malden, MA: Blackwell.

Pepler, D. J., Craig, W. M., Ziegler, S., \& Charach, A. (2009). An evaluation of an anti-bullying intervention in Toronto schools. Canadian Journal of Community Mental Health, 13, 95110.

Pianta, R. C., \& Walsh, D. (1996). High-risk children in schools. Constructing Sustaining Relationships. NY: Routledge.

Polanin, J. R., Espelage, D. L., \& Pigott, T. D. (2012). A Meta-Analysis of School-Based Bullying Prevention Programs' Effects on Bystander Intervention Behavior. School Psychology Review, 41, 47-65.

Sercombe, H., \& Donnelly, B. (2013). Bullying and agency: Definition, intervention and ethics. Journal of Youth Studies, 16, 491-502. 
Siann, G., Callaghan, M., Lockhart, R., \& Rawson, L. (1993). Bullying: Teachers' views and school effects. Educational Studies, 19, 307-321.

Skiba, R. J., \& Knesting, K. (2001). Zero tolerance, zero evidence: An analysis of school disciplinary practice. New directions for youth development, 2001, 17-43.

Skiba, R., \& Peterson, R. (1999). The dark side of zero tolerance: Can punishment lead to safe schools? The Phi Delta Kappa, 80, 372-382.

Smith, P. K., \& Levan, S. (1995). Perceptions and experiences of bullying in younger pupils. British Journal of Educational Psychology, 65, 489-500.

Stockdale, M. S., Hangaduambo, S., Duys, D., Larson, K., \& Sarvela, P. D. (2002). Rural elementary students', parents', and teachers' perceptions of bullying. American Journal of Health Behavior, 26, 266-277.

Swearer, S. M., \& Doll, B. (2001). Bullying in schools: An ecological framework. Journal of Emotional Abuse, 2, 7-23.

Twemlow, S. W., Fonagy, P., \& Sacco, F. C. (2004). The role of the bystander in the social architecture of bullying and violence in schools and communities. Annals of the New York Academy of Sciences, 1036, 215-232.

U.S. Department of Education, National Center for Education Statistics. (2016). "Indicators of School Crime and Safety: 2015 (NCES 2016-079), Figure 11.1."

Vaillancourt, T., McDougal, P., Hymel, S., Kryhsman, A., Miller, J., Stiver, K., \& Davis, C. (2008). Bullying: Are researchers and children/youth talking about the same thing? International Journal of Behavioral Development, 32, 486-495.

Varjas, K., Meyers, J., Bellmoff, L., Lopp, E., Birckbichler, L., \& Marshall, M. (2008). Missing voices: Fourth through eighth grade urban students' perceptions of bullying. Journal of School Violence, 7, 97-118.

Whitted, K. S., \& Dupper, D. R. (2008). Do teachers bully students? Findings from a survey of students in an alternative education setting. Education and Urban, 40, 329-341.

Ziegler, S.., \& Pepler, D. J. (1993). Bullying at school: Pervasive and persistent. Orbit, 24, 2931.

Ziegler, S. \& Rosenstein-Manner, M. (1991). Bullying at school: Toronto in an international context. Research Services No. 196. 


\section{HIGGINS ET AL.}

Ethan M. Higgins, $\mathrm{PhD}$, is an Assistant Professor in the Department of Sociology and Criminology at the University of North Carolina Wilmington. His research primarily focuses on criminal justice personnel, criminal justice research practices, narratives of crime and justice, as well as school violence and response.

Benjamin W. Fisher, $\mathrm{PhD}$, is an Assistant Professor of Criminal Justice at the University of Louisville. His research primarily focuses on school safety, security, and discipline with an emphasis on the role of context.

Maury Nation, Ph.D., is a Professor of Human and Organizational Development at Vanderbilt University. His research focuses school- and community-based youth violence prevention, and neighborhood environments that support positive youth development. 


\section{APPENDIX}

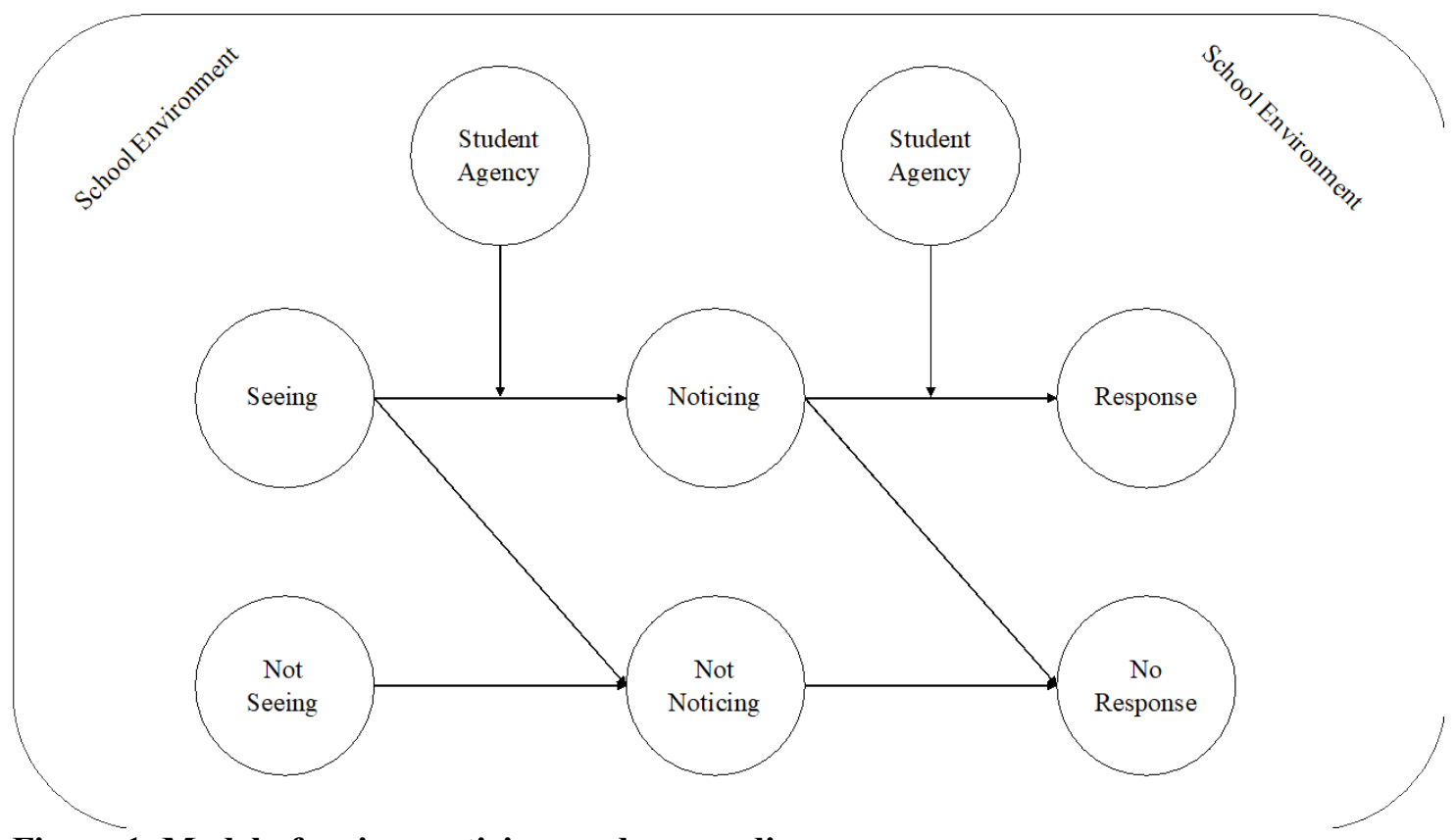

Figure 1. Model of seeing, noticing, and responding. 